\title{
Downtown Delano Urban Design Plan: CRP 203 Work IN SPRING 2008
}

\author{
UMUT TOKER
}

The CRP Department has always encouraged community-outreach projects through studios and special projects. In this article, Umut Toker writes about his work for the City of Delano's downtown, starting with a participatory concept plan in the winter. In the spring, his class developed three urban design proposals.

In fall 2008 the City of Delano approached the City and Regional Planning Department through Department Head Bill Siembieda, expressing their wish for collaboration for Downtown Delano. Following a series of communications it was decided that a participatory effort for idea generation on the future of downtown would be appropriate for the task. A two-step timeline was developed with the Community Development Department of the City of Delano. As a first step, through Winter 2008, a Downtown Concept Plan was developed based on a community participation process with the residents of Delano. As the second step, in Spring 2008 quarter, CRP 203's Section 02 developed three Urban Design Plan Proposals based on the Concept Plan developed earlier. In the following sections of this paper these two phases will be summarized.

\section{Development of the Concept Plan}

Working with the City of Delano Community Development Department, a community participation process was developed that included four workshops. With the participation of Delano residents, downtown business and property owners, as well as the Chamber of Commerce members, four workshops were held. The workshops were held by the Cal Poly team, a team of students and Umut Toker (Figure 1).

The first workshop consisted of an "awareness walk" and focus group interviews. In this process, participants first conducted a tour of downtown, and identified key issues. Using disposable cameras provided by the Cal Poly team, participants took photos of what they liked and disliked about downtown. Once this process was over, participants gathered in the community center and elaborated on their ideas in groups and discussed these with the Cal Poly team.

Analyzing this information, the Cal Poly team developed an idea generation instrument for the second workshop. In this workshop, team members worked with the participants to identify goals and strategies for the future of Delano's downtown. The information collected in this process was analyzed and used to develop the third and fourth workshops. In the third workshop, using instruments designed by the Cal Poly team, participants identified actions that would be required to achieve the goals they identified in the previous activities. The fourth workshop, on the other hand, focused on specifically space related issues. A board game-style "downtown planning game" was developed by the Cal Poly team, which consisted of a plan of existing downtown, and icons on stickers. Each icon identified a desired use, activity or area specified in the previous workshops by the participants. In the fourth workshop,
Umut Toker, Ph.D. is assistant professor at Cal Poly's City and Regional Planning Department.

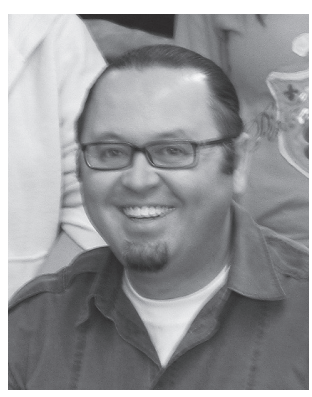

Figure 1

Four community workshops were held by the Cal Poly team during the development of Downtown Delano Concept Plan.

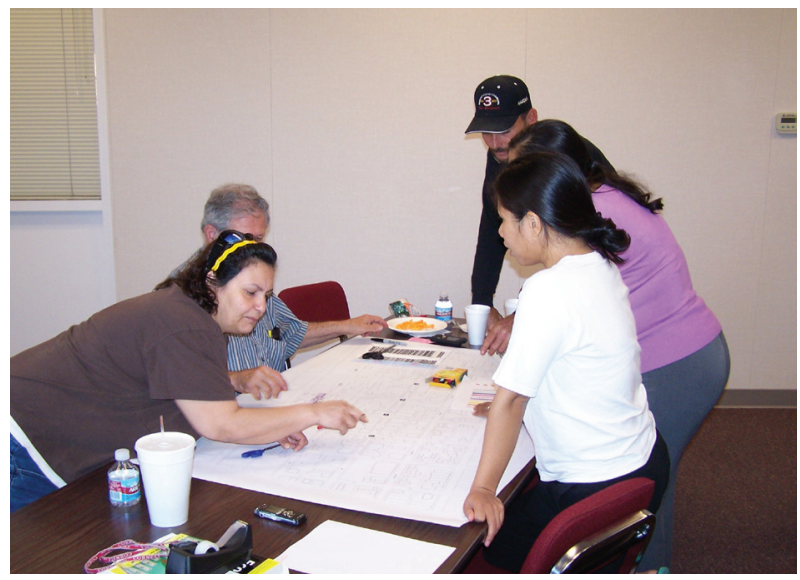




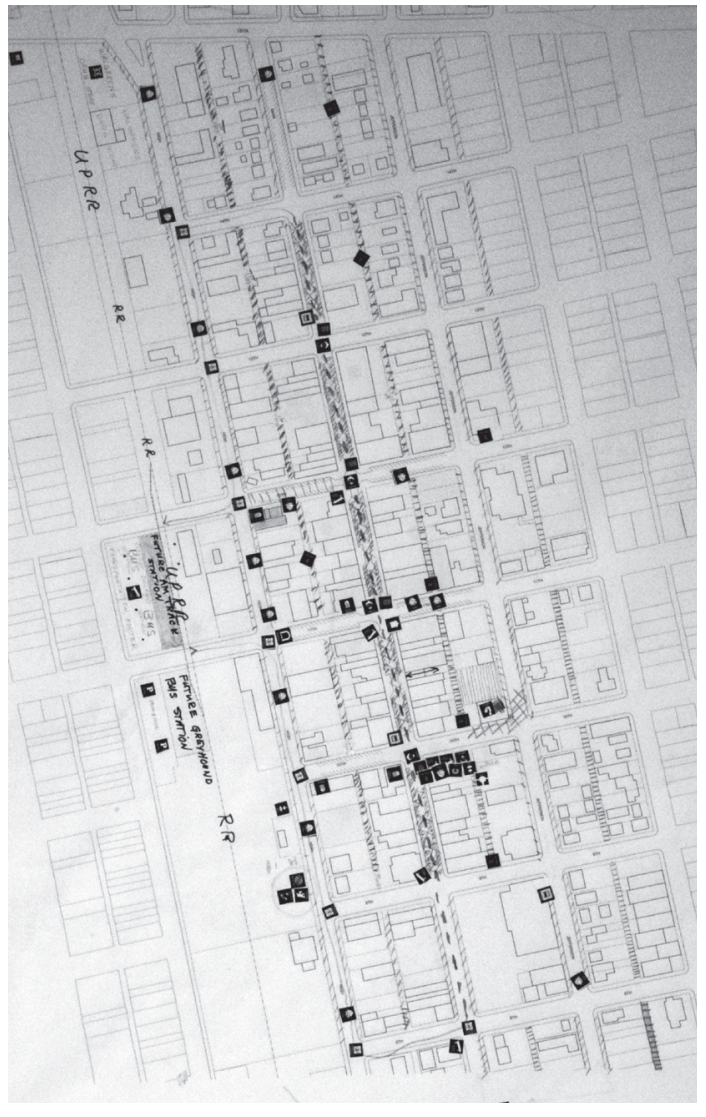

Figure 2

One of the downtown maps created by the community members. site analysis reports. participants were able to plan their "ideal downtown" by participating in this activity.

This process helped the Cal Poly team to develop the Downtown Delano ConceptPlan, whichincludedaseries ofrecommendationsandimplementation strategies for Downtown Delano. The Concept Plan was presented to the City Council, receiving positive feedback. The recommendations developed focused on four areas: (i) land use and economics, (ii) urban form and visual quality, (iii) circulation and transportation, and (iv) public amenities and recreation. These recommendations, which also guided CRP 203's urban design proposals, were completely based on participants' opinions and wishes about the future of their downtown.

\section{Development of Urban Design Plan Proposals}

CRP 203 Urban Design Studio II was supported by the City of Delano to explore the ideas developed for the Concept Plan and develop urban design plan proposals. The class formed three urban design teams, and each of the teams picked one "ideal downtown" scheme developed by Delano residents in workshop four (Figure 2). Then, the concept plan was studied in-depth by the class members. Visits from the Community Development Department Director Keith Woodcock ensured the development of a good understanding of issues about the City and its downtown.

The three urban design teams started work by analyzing the site. The class visited the city, and was briefed by the Community Development Director. Then, a site visit was conducted, during which Director Keith Woodcock gave the class a tour of key issues. Urban design teams were able to conduct an in-depth analysis of the site, visually documenting the existing conditions, and relating their findings to the Concept Plan. Each urban design team then developed

The second step in the process was to analyze a series of urban design plans developed and adopted in California as precedents. During this process urban design teams conducted in-depth analyses of three urban design plans per team, and identified various urban design plan components. This process enabled the urban design teams to identify urban design plan components, and how urban design plans relate to specific plans, general plans, as well as the architectural design process.

Following the site and case analysis steps, urban design teams moved into the conceptual development phase. In this process, the Concept Plan recommendations and Delano residents' input were the driving forces. Urban design teams developed three conceptual diagrams that were accompanied with a series of design concepts, all of which responded to Delano residents' wishes with different solutions (Figure 3).

At this stage, five class representatives visited the Delano Street Fair under Umut Toker's supervision, with posters displaying their conceptual diagrams and design concepts for different areas of downtown. A CRP stand was set up on Main Street. Through the fair, class representatives explained the design concepts they have been developing to residents who stopped by (Figure 4). A large number of residents stopped by the stand, giving input to the project. Boxes were set up for each of the conceptual diagrams, in which visitors could leave written feedback about each proposal. This 


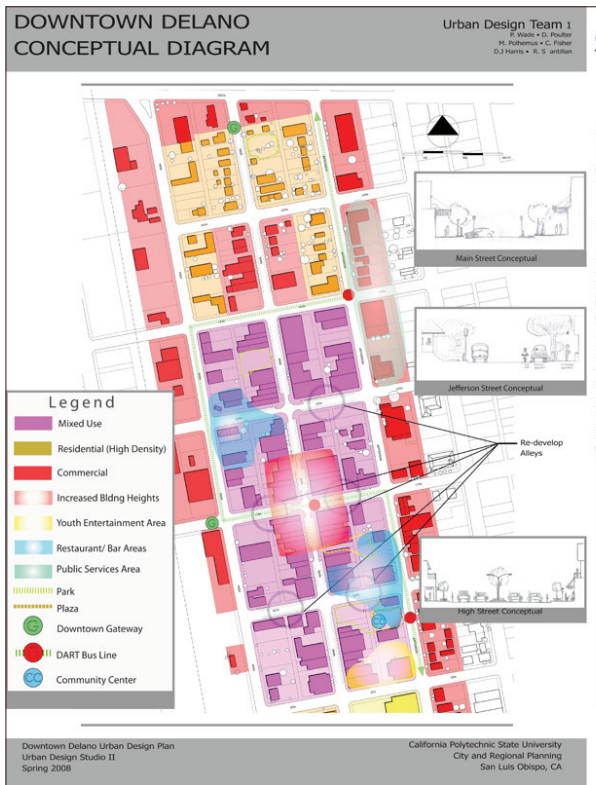

gave the residents the opportunity to leave their comments on note cards; and the students got an additional medium to receive feedback. The information gathered in the street fair was analyzed in class, and the remainder of the quarter was used to develop land use ideas, design guidelines, a conceptual site plan, and visualization of proposals.

In the weeks following the feedback received in the street fair and from the Community Development Director, the urban design teams proceeded into the development of land use concepts and design guidelines. The land use concepts were translated into land use maps by each urban design team. Along with the development of land use plans, planning teams studied the concept of form-based codes (Parolek, Parolek and Crawford, 2008), and developed design guidelines for different areas of downtown. The design guidelines developed by each planning team related to: (i) land use and economic development, (ii) circulation, transportation and street networks, (iii) community amenities and recreation, (iv) urban form, visual quality and massing, (v) standards for street furniture, lighting and signs, and (vi) sustainability and natural resources (Figure 5).

The land use plan and design guidelines were also accompanied by a conceptual site plan developed by each urban design team. The conceptual site plans represented visual accounts of the three urban design plan proposals, and their intended outcomes. Each urban design team's conceptual site plan represented various solutions to the issues communicated by the Delano community (Figure 6).

The urban design teams presented their urban design plan proposals to community members at the end of the quarter (Figure 7). This process enabled the teams to receive feedback about their plan proposals, and the City of Delano to receive a set of ideas that would help enhance their downtown. The

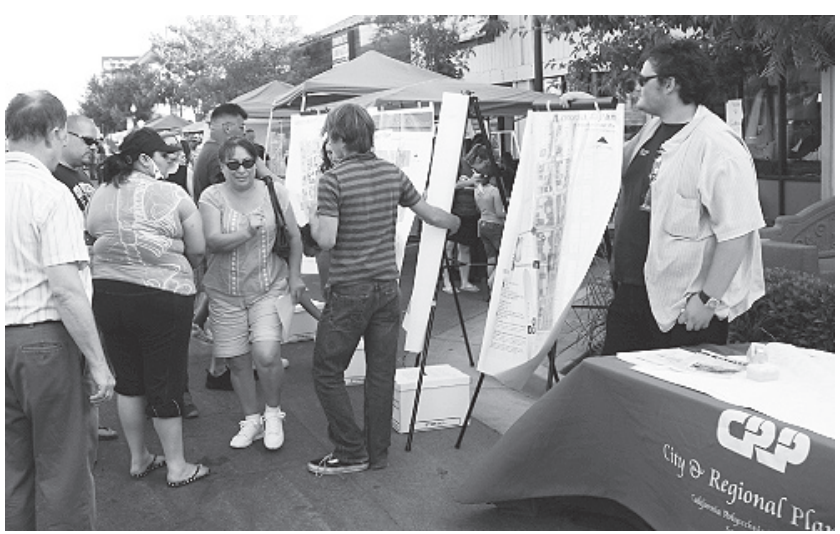

Figure 3

Three conceptual diagrams were created by the urban design teams.

\section{Figure 4}

Class representatives shared their ideas with the Delano community and received feedback during the Delano Street Fair. 

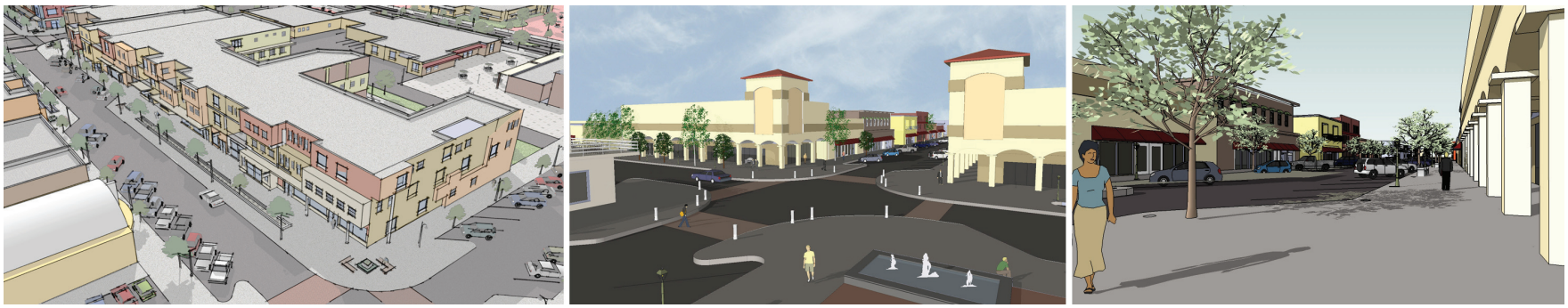

Figure 5

Urban design teams

developed design

guidelines, supplemented by visuals that exemplified design ideas.

three urban design plan proposals were submitted to the City of Delano Community Development Department.

\section{Conclusions}

The development process of urban design plan proposals for Downtown Delano proved a valuable experience for the planning teams. Throughout this process, the students were exposed to the issues and concerns raised by the residents of Delano. Planning teams received feedback about their ideas from community members and city staff.

Figure 6 The experience with the city and community members contributed to the processes of urban

Three conceptual site plans

were developed by the

urban design teams. design and learning. The students were able to study the urban design process, urban design plan components, as well as the community participation process with an added sense of reality

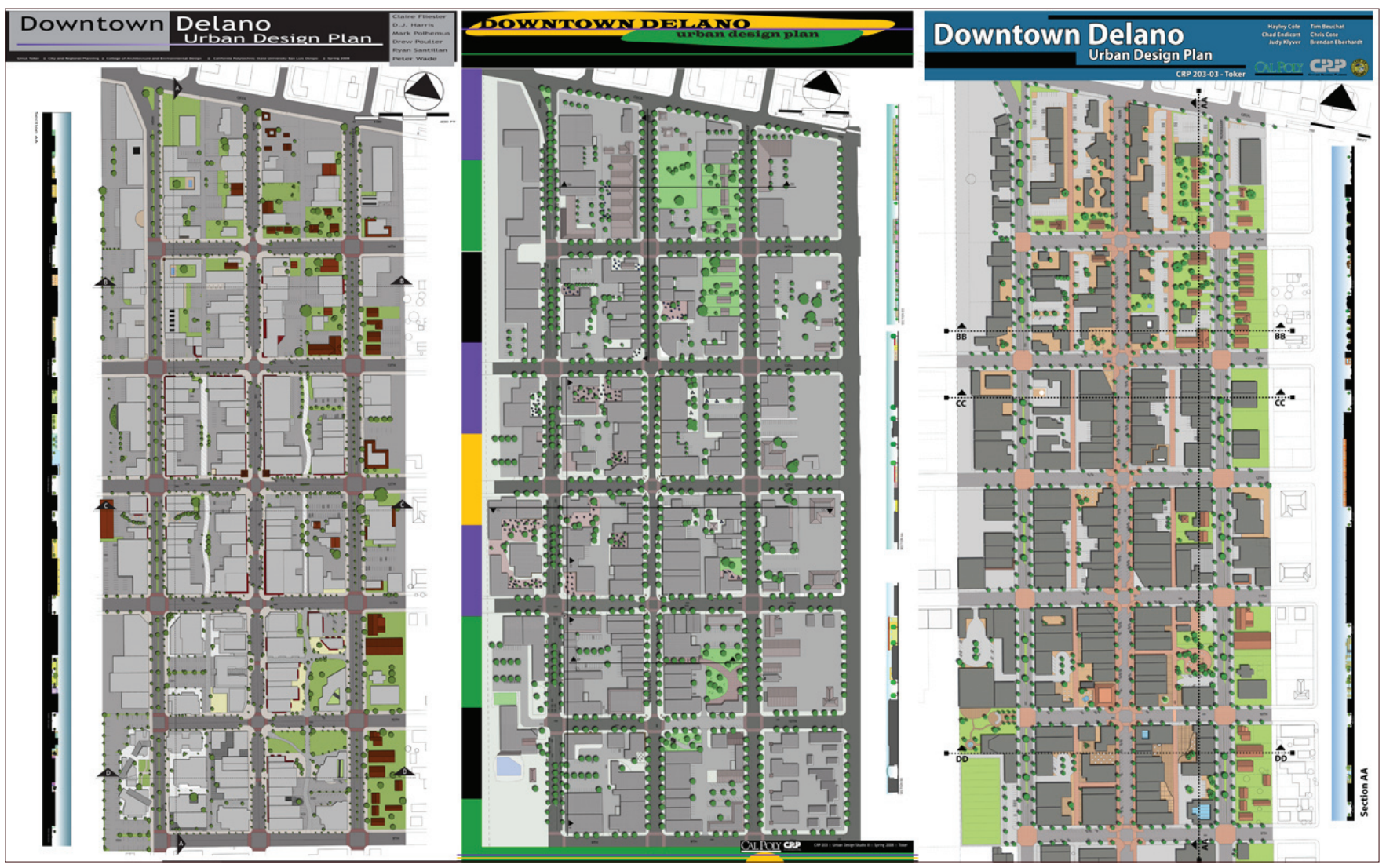


provided by the community. The design concepts and ideas developed by the planning teams related to the residents of Delano, their opinions and their environments.

The community positively received the work of CRP 203. At the end of this process, the Community Development Department expressed their wish to continue working with Cal Poly. Discussions led to the initiation of a new project, the development of a Strategic Plan for the future of Delano. In Fall and Winter of 2008-2009 academic year, the senior project studio (CRP 410-411) undertook this task under the supervision of Kelly Main and Umut Toker.

The hard work of CRP 203 students, and the high quality of their projects helped initiate the start of continued work with the City of Delano. In this way, CRP 203 students not only contributed

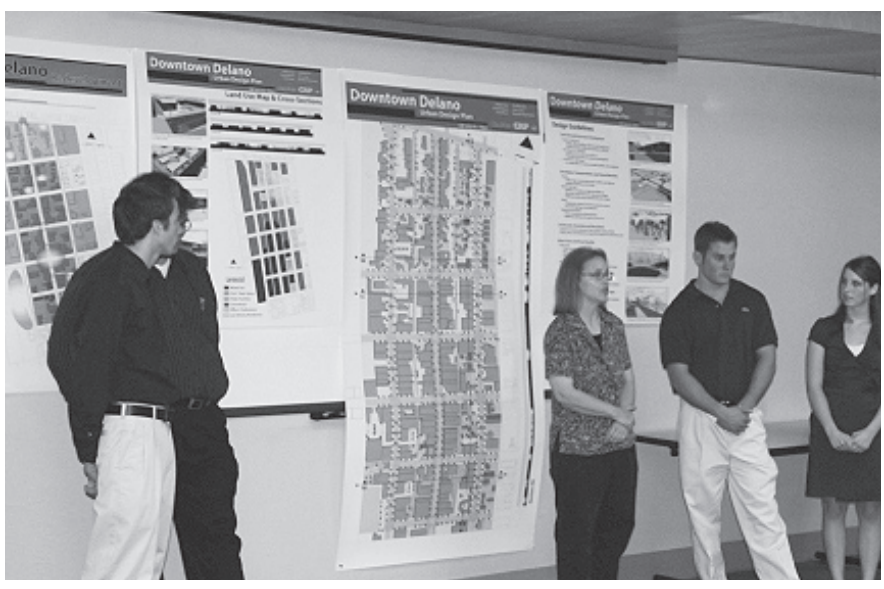

Figure 7

The urban design teams presented their urban design plan proposals to community members at the end of the quarter.

\section{References}

Parolek, D. G., Parolek, K. and Crawford, P. C. 2008. Form-Based Codes: A Guide for Planners, Urban Designers, Municipalities, and Developers. New York: Wiley.

Figure 8

CRP 203 Downtown Delano urban design teams in the studio.

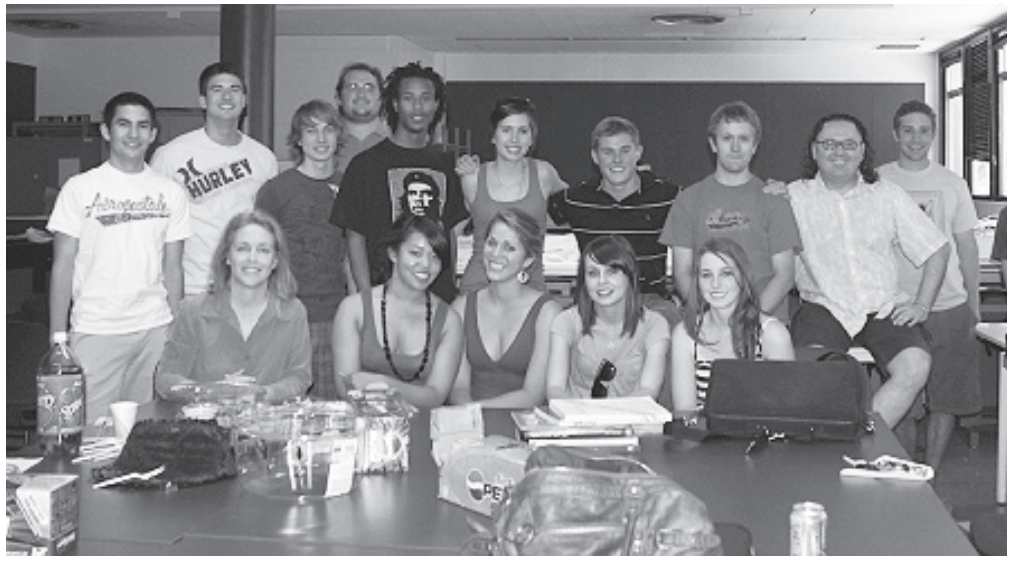

